\title{
Genome wide association mapping of stripe rust resistance in Afghan wheat landraces
}

\author{
Alagu Manickavelu ${ }^{1,10^{* \#}}$, Reem Joukhadar, ${ }^{2,3}$, Abdulqader Jighly ${ }^{2,4,5}$, Caixia Lan ${ }^{6}$, Julio Huerta-Espino ${ }^{7}$, Ahmad \\ Shah Stanikzai ${ }^{1,8}$, Andrzej Kilian ${ }^{9}$, Ravi P. Singh ${ }^{6}$, Tomohiro Ban ${ }^{1}$ \\ ${ }^{1}$ Kihara Institute for Biological Research, Yokohama City University, Yokohama - 2440813, Japan \\ ${ }^{2}$ AgriBio, Centre for Agribioscience, DEDJTR, 5 Ring Road, Bundoora, Vic. 3083, Australia \\ ${ }^{3}$ School of Botany, La Trobe University, Bundoora, Vic. 3083, Australia \\ ${ }^{4}$ School of Applied Systems Biology, La Trobe University, Bundoora, Vic. 3083, Australia \\ ${ }^{5}$ The International Center for Agricultural Research in the Dry Areas (ICARDA), Aleppo, Syria \\ ${ }^{6}$ CIMMYT, Apdo. Postal 6-641, 06600, Mexico \\ ${ }^{7}$ Campo Experimental Valle de México, INIFAP, Chapingo, Estado de México, México \\ ${ }^{8}$ Ministry of Agriculture, Irrigation and Livestock, Afghanistan \\ ${ }^{9}$ Diversity Arrays Technology Pvt. Ltd., Australia \\ ${ }^{10}$ Present address: Department of Genome Science, School of Biological Science, Central University of Kerala, \\ Kasaragod - 671314, Kerala, India \\ \# Contributed equally \\ * Corresponding author \\ Dr. A. Manickavelu, Email: manicks@yokohama-cu.ac.jp, amanicks@gmail.com
}

(C) 2016. This manuscript version is made available under the Elsevier user license http://www.elsevier.com/open-access/userlicense/1.0/ 


\begin{abstract}
Mining of new genetic resources is of paramount importance to combat the alarming spread of stripe rust disease and breakdown of major resistance genes in wheat. We conducted a genome wide association study on 352 unutilized Afghan wheat landraces against stripe rust resistance in eight locations. High level of disease variation was observed among locations and a core-set of germplasm showed consistence performance. Linkage disequilibrium (LD) decayed rapidly $\left(\mathrm{R}^{2} \approx 0.16\right.$ at $0 \mathrm{cM}$ ) due to germplasm peerless diversity. The mixed linear model resulted in ten marker-trait associations (MTAs) across all environments representing five QTL. The extensively short LD blocks required us to repeat the analysis with less diverse subset of 220 landraces in which $\mathrm{R}^{2}$ decayed below 0.2 at $0.3 \mathrm{cM}$. The subset GWAS resulted in 36 MTAs clustered in nine QTL. The subset analysis validated three QTL previously detected in the full list analysis. Overall, the study revealed that stripe rust epidemics in the geographical origin of this germplasm through time have permitted for selecting novel resistance loci.
\end{abstract}

\title{
Keywords:
}

Afghan wheat landraces, Stripe rust, GWAS, Genotyping-by-sequencing 


\section{Introduction}

Stripe rust, caused by Puccinia striiformis f. sp. tritici (Pst), is one of the most destructive fungal diseases that can limit wheat production worldwide. Grain yield losses can reach $40 \%$ and up to $100 \%$ under severe infections [1]. Moreover, the recent breakdown of the race-specific resistance gene $\operatorname{Yr} 27$, a gene present in several commercial varieties in Asia and Africa, caused yield losses between $10 \%$ and $80 \%$ in many countries of Central West Asia and North Africa (CWANA) region [2]. Managing stripe rust epidemics is difficult and using resistant cultivars carrying both major and minor resistance genes is the best way to control stripe rust [3]. The continuous evolution of pathogens creates a need to develop new resistance cultivars through time. Two type of wheat resistance genes have been found and deployed in different breeding programs which are 1) race-specific and 2) race-nonspecific genes $[4,5]$. Race specific genes usually shows major resistance against $P s t$ while race nonspecific genes are minor genes that are usually expressed in the adult stage and supposed to be affective against all Pst races, theoretically. Due to the rapid evolution of the rust pathogen population, different breeding programs are now focusing on pyramiding both race-specific and race nonspecific resistance genes to improve the resistance durability [6,7]. So far, about 67 designed and 42 temporarily named stripe rust resistance genes have been reported [8]. Unfortunately, many of those utilized resistance genes in different breeding programs are no longer effective against different new Pst races [9], which has alarmed the need for new sources of resistance deployment including landraces.

Developing new stripe rust resistant wheat varieties requires continuous exploration of new genetic resources. Afghan landraces, untapped genetic resources collected and preserved by Dr. Hitoshi Kihara, are among the germplasms never characterized so far to know their potential for contributing stripe rust resistance. The place of origin and the previous study on genotypic characterization offer the possibility to mine new resistance sources for stripe rust $[10,11]$. Also the recent report showed the Himalayan and surrounding region as centre of origin of Pst virulence races [9]. Zeven [12] well documented the co-evolution of landraces along with stress and their importance to choose as a breeding and/or pre-breeding material for crop improvement. For each site and for each year their composition becomes adapted to the conditions of that site and that year. These adaptations have taken place by changing the frequencies of phenotypes and hence genotypes for self-fertilizing by absorbing new genotypes either introduced from elsewhere or else which have originated by mutation or by low degree of interplant hybridization. It is necessary to consider these special qualities of landraces that have enabled man to obtain sufficient food to survive during some 10,000 years [13].

Genome-wide association studies (GWAS) utilize linkage disequilibrium (LD) in a set of genotypes to identify quantitative trait loci (QTL), thus it exploit historical recombination since the population diversion. Recent domestication of wheat from a narrow selection of wild relatives caused longer LD blocks with an advantage of the need for smaller number of markers to cover the full genome [14]. GWAS has been used successfully in mapping QTL for different traits in wheat. In specific to stripe rust, Zegeye [15], Maccaferri [16], Naruoka [17], Jighly [18] carried out GWAS using different germplasm but not exclusively landraces. 
This study utilized 352 Afghan common wheat (Triticum aestivum L.) landraces in order to evaluate their adult-plant response to stripe rust infection under field conditions in multiple environments and identify genomic regions associated with stripe rust resistance in order to utilize them for breeding purposes.

\section{Materials and methods}

\section{1. Plant materials}

The study included 352 Afghan wheat landraces that well-germinated from the total collection of 446 preserved at the Kihara Institute for Biological Research (here after mentioned as Kihara Afghan Wheat Landraces KAWLR) (Table S1 - The passport details reported in Manickavelu [11]. These landraces were collected from 17 provinces and 160 collection sites. The accessions were grouped as $65 \%$ spring, $14 \%$ facultative and $21 \%$ winter wheat. The harvested seeds from 2011 crop season of Japan were distributed for all evaluations.

\subsection{Stripe rust adult-plant field evaluation}

The KAWLR set was evaluated under natural disease epidemics in nine field trials performed at six locations from 2011-2014 (Table 1). In 2011, the material was planted in winter cycle at Toluca research station of CIMMYT in Mexico and fall sowing of Afghan along with susceptible checks (cvs. Morocco and Avocet). The spreader lines were planted at each location helped uniform disease spread. Natural heavy incidence occurred on both places and the susceptible checks produced large quantities of urediniospores to the spread the disease on the KAWLR set. The seed multiplied at each location was used to expand the evaluation at four locations in Afghanistan and at Toluca, Mexico during 2012. In Afghanistan, the disease severity varied among locations and time of sowing where the late sowing in Badambagh research station showed heavy incidence, however the disease incidence was low in Herat. In Mexico 2012 trial, materials were planted in Toluca under artificial inoculation resulting in excellent yellow rust development providing good data. The spreaders and hills were inoculated with a mixture of Pst isolates Mex96.11 and Mex08.13 approximately one month after sowing. In 2013, only one trial was conducted at Herat. In all field trials in Afghanistan, germplasm were evaluated in non-replicated single row plots whereas in Toluca two rows were sown. Field plots consisted of $0.7-\mathrm{m}$ paired rows with approximately 60 plants of each line. A mixture of six susceptible wheat lines derived from an Avocet/Attila cross, Morocco and Avocet nearisoline for gene Yr31 was used as the spreader in field trials. In order to get uniform and enough inoculum, the spreaders were planted around the experimental area and as hill plots in the middle of a $0.3-\mathrm{m}$ pathway on one side of each experimental plot.

Stripe rust reactions were rated using the following two metrics: 1) The 0-4 scale for reaction type (DR), as described by Line and Qayoum [19], and 2) Disease severity (DS), rated as a percentage of leaf area in the infected row according to the modified Cobb Scale [20]. Data collection was initiated when stripe rust severity on the susceptible parent Avocet reached $80-90 \%$ in Toluca. The first note was recorded when the susceptible check Avocet displayed approximately $80 \%$ severity and repeated about a week later when it reached $90-100 \%$. To calculate the coefficient of infection (CI), DS score were multiplied by $0.2,0.4,0.6,0.8$, or 1.0 which stand for IT of 
resistance $(R, 0)$, moderately resistance $(M R, 1)$, intermediate $(M, 2)$, moderately susceptible (MS, 3) or susceptible (S, 4), respectively [61].

\subsection{Genotyping-by-sequencing (GBS) genotyping}

Genomic DNA was extracted from the leaves of individual accession and genotyped with GBS $1.0 \mathrm{~V}$ array containing both SNP and DArT markers (Triticarte Pvt. Ltd., Australia). The complete details were reported in Manickavelu [11].

\subsection{Phenotypic data analysis}

Analysis of variance (ANOVA) was estimated for stripe rust response data collected across all locations. The GGE bi-plot (genotype $\times$ environment interaction) implemented in the R package GGEBiplotGUI [21] was calculated for CI scores to estimate the stability of wheat genotypes in response to the stripe rust infection across all environments. CI scores were reversed (100 - the score) for the GGE analysis so resistant genotypes can have higher scores for easier interpretation of the graph following Yan [62]. The model was scaled with within trait standard deviation as we are dealing with heterogeneous environments [62].

\subsection{Linkage disequilibrium}

Pairwise measures of LD $\left(\mathrm{R}^{2}\right)$ between SNP markers were estimated as described by Hedrick [22] and Weir [23]. Only markers with minor allele frequency $(\mathrm{MAF})>5 \%$ were used for $\mathrm{LD}$ estimation. The $\mathrm{R}^{2}$ values were plotted as a function of genetic distance $(\mathrm{cM})$ and the second LOESS decay curve fitted using the square root transformation. The map distance at which LD fell below critical $\mathrm{R}^{2}$ thresholds to define the confidence intervals of QTL detected in this study was estimated following [24].

\subsection{Association mapping}

The association of SNP and stripe rust resistance phenotype was carried out using a unified mixed-model approach (MLM) as implemented in the genome association and prediction integrated tool (GAPIT) [25]. The MLM model used here accounts for type I errors due to considering genetic relatedness or kinship (K) within the mapping population, the effect of population structure $(\mathrm{Q})$, as covariates [26,27]. The $\mathrm{Q}$ matrix was obtained from principal components obtained from the PCA analysis while the K matrix quantifies the probability that two homologous loci are identical by descent following VanRaden method implemented in GAPIT [28]. The optimal number of PCs was estimated using the Bayesian information criterion (BIC) implemented in GAPIT. The multi environment testing was conducted by fitting all environments together in one analysis in TASSEL for DS, DR and CI.

Significant associations between markers with MAF $>5 \%$, and stripe rust resistance were determined based on the initial F test. Significant marker trait associations were declared using Bonferroni correction. However, Bonferroni correction was originally designed for independent tests while molecular markers are dependent due to genetic linkage leading to false negative outcomes when using it. To avoid that, markers with tight $L D\left(\mathrm{R}^{2}>0.95\right)$ were considered dependent and were represented by a single marker in the Bonferroni correction. However, 
supplementary tables 3 and 4 contains suggestive QTL up to $\mathrm{P}<5 \times 10^{-4}$. The map locations of DArTSeq markers used in this study were obtained from the consensus genetic map of wheat provided by the supplier. The databases http://cmap.cimmyt.org/cgi-bin/cmap; https://ccg.murdoch.edu.au/cmap/ as well as the genetic maps of Detering [29], Jighly [30] and Lowe [5] were used to compare our QTL positions with previously reported QTL as the provided consensus map from Triticarte Pvt. Ltd., Australia involves the traditional DArT markers that were useful for comparison.

\section{Results}

\subsection{Phenotypic variation}

All environments showed high resistance variation for the germplasm except for Herat in both seasons (Figure S1). Interestingly, the late planting in BB_12-13 showed more disease reaction than the early one while the early planting showed higher disease severity response leading to a higher overall susceptibility in the early planting (Figure S1). Table S2 shows the ANOVA results for the disease reaction, severity and transformed score according to coefficient or resistance across all environments. In all locations, significant variations between the genotypes were found for DS, DR and the coefficient with $\mathrm{P}<2 \times 10^{-16}$ in all ANOVA tables (Table S2) while the variation among environments were significant in both DS $\left(\mathrm{P}=3 \times 10^{-5}\right)$ and $\mathrm{DR}(\mathrm{P}=0.001)$ but not in the coefficient $(\mathrm{P}=$ 0.29). Interestingly, the interaction between the genotypes and the environments were not significant in all cases (Table S2). The first two principal components in the GGE bi-plot analysis explained together about $71.7 \%$ of the total variation. Moreover, many landraces clustered close to the center in the GGE bi-plot analysis while a considerable proportion of the landraces $(\sim 31 \%)$ were close to the ideal genotype (Figure 1).

\subsection{Marker coverage, kinship relations and linkage disequilibrium}

Out of the 27,836 applied SNPs, 10,204 (about 36.7\%) were polymorphic in our germplasm with MAF > $5 \%$ and missing data $<15 \%$. Only 7,216 SNPs (about 70.7\%) out of the polymorphic markers have map positions of which 2,662 were found on A genome, 3,553 on B genome and 1,001 on D genome. Chromosome 4D had the lowest number of markers with 41 SNPs followed by 5D with 79 SNPs while chromosomes 2B and 3B had the highest number of SNPs with 742 and 600, respectively. Figure 2 shows a heat map of the kinship relation among 352 Afghan landraces sorted based on the phylogenetic relations.

The critical $\mathrm{R}^{2}$ for the full list was equal to 0.155 . Over all chromosomes, $\mathrm{LD}$ started to decay with $\mathrm{R}^{2} \approx$ 0.16 at $0 \mathrm{cM}$. Considering each genome individually, we found that $\mathrm{R}^{2}$ started with a value larger than 0.2 only on $\mathrm{D}$ genome; while only chromosomes $1 \mathrm{D}, 2 \mathrm{~A}, 2 \mathrm{D}, 3 \mathrm{D}, 4 \mathrm{~A}, 4 \mathrm{~B}, 4 \mathrm{D}, 5 \mathrm{~A}, 5 \mathrm{D}, 6 \mathrm{~A}, 6 \mathrm{D}, 7 \mathrm{~A}$ and $7 \mathrm{D}$ started with $\mathrm{R}^{2}>0.16$ (Figure S2, S3). The small LD blocks required us to select a subset of landraces with lower genetic diversity and higher kinship relations in order to extend the LD blocks for the association analysis. For this reason we selected a subset of 220 genotypes by excluding the landraces in the red square in Figure 2 . The critical $\mathrm{R}^{2}$ value for the subset were about 0.197 . This step raised the $\mathrm{R}^{2}$ value to reach 0.2 at $\sim 0.3 \mathrm{cM}$. Moreover, all chromosomes started to decay with $R^{2}$ values higher than or very close to 0.2 with larger LD blocks except for chromosomes $1 \mathrm{~B}, 3 \mathrm{~A}, 3 \mathrm{~B}$ and $6 \mathrm{~B}$ (Figure S4, S5). 


\subsection{Association analysis}

The association analysis was conducted on both the full set and the subset. Considering SNPs with high $\mathrm{R}^{2}$ values ( $>0.95)$ as dependent, we ended with 715 independent markers for the subset and 1404 markers for the full set. This shifted the significant $\mathrm{P}$ value threshold using Bonferroni correction to $7 \times 10^{-5}$ for the subset and $3.5 \times 10^{-5}$ for the full analyses. Subset analysis identified 36 MTAs resulted from 24 associated markers. Twelve markers were distributed on nine different genomic regions while the other twelve had unknown genomic positions (Table 2). On the other hand, the full list analysis detected eight associated markers with ten MTAs. Five out of the eight distributed on 5 different genomic regions while the rest have unknown positions (Table 2). Figures S6 and S7 shows the Manhattan plots and QQ plots for the expected and observed P values of the full analysis for all locations respectively; while figures S8 and S9 shows the same plots for the subset analysis. The number of detected MTAs is acceptable comparing to QQ plots (Figure S7, S9). Chromosome 1B is the only chromosome that harbored two QTL while each of the chromosomes 1A, 2A, 3A, 3B, 4A, 5A, 5B, 6A and 7B had one QTL. Only three genomic regions were common between both analyses which were distributed on chromosomes 1B, 2A, and 5B.

A single QTL for BB-12 was detected in each of the early and the late seasons. The early season QTL was detected in the subset analysis while the late season QTL was detected in the full analysis but both QTL has unknown positions. Kabul 2011 had one QTL on chromosome 5A plus one MTA with unknown position revealed by the subset analysis. GWAS for Toluca 2011 revealed two QTL on 2A and 7B of which 2A QTL was detected using both analysis which the 7B QTL was detected in the subset analysis only. Moreover, the subset analysis identified five MTAs with unknown positions of which two were shared with the full analysis. Herat season 2012 had the highest number of MTAs representing eight QTL and five MTAs with unknown positions. QTLs located on chromosomes 1A, 3A, 4A and 6A were tagged only using the subset analysis while the distal 1B QTL and the 3B QTL were detected in the full analysis only. The proximal 1B QTL and the 5B QTL were common in both analyses. Finally, fitting all environment together in TASSEL detected a single QTL in the subset analysis on chromosome 6A.

\section{Discussion}

Preserving, characterizing and utilizing of wheat landraces have gained more interest in the past few decades. Preserved landraces can form a "reservoir for adaptive genes" to be exploited by different breeding programs. Since 1955, Dr. Hitoshi Kihara initiated different scientific expeditions to collect Afghan Wheat landraces [31]. Those landraces were preserved in Kihara Institute for Biological Research and they have got an extensive molecular characterization to describe their broad diversity [11,32]. In order to fully understand the importance of Afghan wheat landraces, field evaluation for different traits as well as abiotic and biotic stress responses are required. In this research we reported the response of 352 KAWLR against yellow rust resistance under diverse environments in Afghanistan and Mexico (Table 1). The ANOVA results indicated the huge diversity in stripe rust response in the landrace panel in concordance with the previous genetic diversity study on the same materials with molecular markers $[10,11]$. Sufficient numbers of resistant landraces could be found across environments that could be used to increase the genetic diversity for stripe rust resistance in regions threatened by the breakdown of the resistance gene Yr27. 
The GGE biplot analysis (Figure 1) showed that both seasons in Herat and Kabul were similar to each other while the BB seasons clustered around the average. SBES was isolated away from other environments which reflect the diversity of the environment used in this study. Although landraces usually have lower stability than improved cultivars when testing in multiple environments, considerable proportion of the landraces showed high stability across different environments comparable to that stability in ICARDA elite spring wheat [18] and ICARDA elite winter/facultative wheat [33] which reflect the importance of this germplasm. Moreover, lots of landraces were placed close to the position of the ideal genotype with performance above the mean which support the novelty of this germplasm as well. A core-set of 21 KAWLR lines, showing consistent performance across environments, was identified based on the multisite performance results.

Calculating LD decay for the 352 genotypes resulted in a rapid decay started with $\mathrm{R}^{2} \approx 1.6$ for the overlapped markers on the genetic map. Unfortunately, the physical positions of the SNPs are not available except for the chromosome 3B which made it impossible to accurately estimate the LD block size. Breseghello and Sorrells [24] previously estimated that the critical value of $\mathrm{R}^{2}>0.2$ is due genetic linkage which means that our SNPs are possibly not enough to cover the genome in our germplasm. For this reason, we selected a subset of 220 landraces with lower genetic diversity and higher mean kinship in order to get larger LD blocks for better MTA detection in such a diverse germplasm. The $\mathrm{LD}$ decayed below $\mathrm{R}^{2}=0.2$ at $0.3 \mathrm{cM}$ which made our coverage more appropriate for GWAS. To the best of our knowledge, the LD decay reported in this germplasm is lower compared to all previous studies on different wheat germplasms which ranged from 1-2 cM to about $40 \mathrm{cM}$ [14,18,33-39]. For the association analysis, we used both the full list and the subset to end with three types on associations: 1) in the full analysis only for rare QTL or QTL don't exist in the subset germplasm 2) in the subset analysis only for markers with a bit larger interval distance from the correspondence genes 3) common QTL which can be considered as consistent QTL.

A number of the detected QTL can be considered as novel genes that have not been described previously including the QTL on 4AL, 6AS, and 7BS. The result of Mexico 2012 trial further supported the novelty as we have used the isolate of Mex08.13 belongs to the lineage of the aggressive YR race first detected in California, US, and possesses virulence to genes $\operatorname{Yr}(2), 6,7$, (8), 9, 31, \& A, whereas Mex96.11 is virulent to $\operatorname{Yr} 2,6,7,9,27 \&$ A. Thus, the QTL identified in this study is not Yr27. However we may have more novel QTL than those as we lack the genomic information to compare our findings with previous reports. The improvement of the wheat reference genome will facilitate better. Two different QTL was previously reported on 1AL of which QRYr1A.2 [40,41] seems to be in the region of our QTL. Rosewarne [42] reported a QTL QRYr1B.1 very close to the centromere in the regions of our first QTL on the same chromosome. Different studies reported different QTL on 1BL [42-46]. However, without physical locations or a consensus genetic map for different marker types, it will be very hard to determine which of our other five QTL on 1BL have been previously identified in our germplasm. A large region on chromosome 2AS ( $45 \mathrm{cM})$ was reported to carry stripe rust resistance in which we detected our QTL [47,48]. The 3AS QTL detected by the marker 1081763 seem to be equivalent to Lillemo [44] QTL. A minimal of three QTL was detected on both arms of the chromosome 3B [41]. The present study found eight different QTL distributed along the chromosome. 
The distal QTL on chromosome 4AL detected by the marker 1863706 seems to be the same QTL reported by Ramburan [50]. The proximal QTL on chromosome arm 5AL is in concordance with Chhuneja [52] QTL while the distal QTL on the same arm was previously reported by Lan [53] and Ren [40]. The centromeric region of the chromosome 5B carries the QTL QRYr5B.1 [54-58]. Here, we reported a common QTL in this region. We detected one QTL on chromosome arm 6AS which is similar to that reported by Lin and Chen [43] and Hao [57]. Finally, we found two QTL on chromosome arm 7BL the proximal one is close to that reported by Lin and Chen [43] and Bariana [47] while the distal one is in the region of the QTL reported by Rosewarne [42,46] and Ren [40].

The number of QTLs identified in this study is comparable with the result of Maccaferi [13] who used 875 nonredundant accession for rust-GWAS analysis. Especially identification of three new QTLs from the new wheat germplasm is worthy to consider. The greater number of detected QTL also may be the result of more complex environmental conditions found in the field compared to the controlled environment. This is due to the huge genetic diversity in this germplasm and the prevailing adaptation mechanism of landraces [10,11,32]. Also the combined vision of Pst virulent races origin around Himalayan region and the co-evolution nature of landraces along with stress showed the importance of this study and identification of new resistance sources for stripe rust $[9,12]$. The in silico analysis reported the probable function of QTLs. The much improved A. tauchii genome sequence and their annotation helped to find the wheat gene function of marker sequence. Besides annotation as hypothetical protein, there are linked markers resulted as Leucine-rich, Glutathione S transferase, NAC domain containing protein \& WRKY transcription factors. This functional analysis is just a starting point to utilize the marker sequence and convert them as functional markers.

The rust mapper (http://rusttracker.cimmyt.org/) and Hovmoller [9] reported the presence and spreading of new virulence races of stripe rust. These races have increased aggressiveness and the ability to produce more spores at higher temperature than before [59]. It caused serious stripe rust epidemics in areas previously considered unsuitable for disease, and have turned stripe rust into one of the most economically damaging wheat pathogen [60]. Hence, the

current study of identifying new Pst resistance genes by GWAS of KAWLR make a valuable addition to the wheat gene pool of breeding programs to develop new resistance variety. Especially in Afghan the Pst race study has not been carried out which speculated the high possibility of races mixture that helped to check the potential of landraces in their origin. In addition, the use of adult plants in our field studies can result in the detection of additional adult plant resistance genes that are not effective at the seedling stage.

\section{Authors' contribution}

AM designed the work. AM, RJ, AJ carried out data analysis. $\mathrm{CL}, \mathrm{JH}, \mathrm{AS}$, RPS done the field screening in respective places. AK helped for GBS array mapping. AM, RJ and AJ wrote the paper.

\section{Acknowledgements}

This work is the outcome of SATRPES-Afghan project funded by JICA (Japan International Co-operation Agency) and JST (Japan Science and Technology). 


\section{References}

[1] S. Mumtaz, IA. Khan, S. Ali, B. Zeb, A. Iqbal, Z. Shah, ZA. Swati, Development of RAPD based markers for wheat rust resistance gene cluster (Lr37-Sr38-Yr17) derived from Triticum ventricosum L, Afr J Biotechnol 8 (2009) 1188-1192.

[2] M. Solh, K. Nazari, W. Tadesse, CR. Wellings, The growing threat of stripe rust worldwide Borlaug global rust initiative (BGRI) conference (2012), Beijing.

[3] XM. Chen, Review article: high-temperature adult-plant resistance, key for sustainable control of stripe rust Am J Plant Sci 4(2013) 608-627.

[4] XM. Chen, Epidemiology and control of stripe rust (Puccinia striiformis f. sp tritici) on wheat, Can J Plant Pathol 27(2005) 314-337.

[5] I. Lowe, DL. Jankuloski, S. Chao, X. Chen, D. See et al, Mapping and validation of QTL which confer partial resistance to broadly virulent post-2000 North American races of stripe rust in hexaploid wheat, Theor Appl Genet 123(2011) 143-157.

[6] RP. Singh, J. Huerta-Espino, S. Rajaram, Achieving near immunity to leaf and stripe rusts in wheat by combining slow rusting resistance genes, Acta Phytopathol Hun 35(2000) 133-139.

[7] RP. Singh, J. Huerta-Espino, HM. William, Genetics and breeding for durable resistance to leaf and stripe rusts in wheat, Turk J Agric For 29(2005) 121-127.

[8] RA. McIntosh, Y. Yamazaki, J. Dubcovsky, WJ. Rogers, CF. Morris et al, Catalogue of gene symbols for wheat in 12th International Wheat Genetics Symposium, edited by R.A. McIntosh, Yokohama, Japan (2013).

[9] MS. Hovmoller, S. Walter, RA. Bayles, A. Hubbard, K. Flath, N. Sommerfeldt, M. Leconte, P. Czembor, J. Rodriguez-Algaba, T. Thach, JG. Hansen, P. Lassen, AF. Justesen, S. Ali, C. de Vallavieille-Pope, Replacement of the European wheat yellow rust population by new races from the centre of diversity in the near-Himalayan region, Phytopathology (2015) doi: 10.1111/ppa.12433

[10] A. Manickavelu, S. Niwa, K. Ayumi, K. Komatsu, Y. Naruoka, T. Ban, Molecular evaluation of Afghanistan wheat landraces, Plant Genetic Resources: Characterization and Utilization 12(S1) (2014a) S31-S35.

[11] A. Manickavelu, A. Jighly, T. Ban, Molecular evaluation of orphan Afghan common wheat (Triticum aestivum L.) landraces collected by Dr. Kihara using single nucleotide polymorphic markers, BMC plant biology 14(2014b) 320 . 
[12] AC. Zeven, Landraces: A review of definitions and classification, Euphytica 104(1998) 127-139.

[13] AC. Zeven, Domesticatie en evolutie van de kultuurplant. Wageningen Agricultural University, Dept of Plant Breeding, Mimeographed Lecture Notes (1975) 177 pp.

[14] S. Chao, W. Zhang, J. Dubcovsky, M. Sorrells, Evaluation of genetic diversity and genome-wide linkage disequilibrium among US wheat (Triticum aestivum L.) germplasm representing different market classes, Crop Sci 47(2007) 1018-1030.

[15] H. Zegeye, A. Rasheed, F. Makdis, A. Badebo, FC. Ogbonnaya, Genome-wide association mapping for seedling and adult plant resistance to stripe rust in synthetic hexaploid wheat, PloS one 9(8) (2014) e105593.

[16] M. Maccaferri, J. Zhang, P. Bulli, Z. Abate, S. Chao, D. Cantu, E. Bossolini, X. Chen, M. Pumphrey, J. Dubcovsky, A Genome wide association study of resistance to stripe rust (Puccinia striiformis f.sp. tritici) in a worldwide collection of hexaploid spring wheat (Triticum aestivum L.), G3 5 (2015) 449-465.

[17] Y. Naruoka, KA. Garland-Campbell, AH. Carter, Genome-wide association mapping for stripe rust in US Pacific Northwest winter wheat, Theor Appl Genet 128(2015) 1083-1101.

[18] A. Jighly, BC. Oyiga, F. Makdis, K. Nazari, O. Youssef, et al, Genome-wide DArT and SNP scan for QTL associated with resistance to stripe rust (Puccinia striiformis f. sp. tritici) in elite ICARDA wheat (Triticum aestivum L.) germplasm, Theor Appl Genet 128(7) (2015) 1277-1295.

[19] RF. Line, A. Qayoum, Virulence, aggressiveness, evolution and distribution of races of Puccinia striiformis (the cause of stripe rust of wheat) in North America 1968-87. Technical bulletin (USA) (1992).

[20] RF. Peterson, AB. Campbell, AE. Hannah, A diagrammatic scale for estimating rust intensity on leaves and stems of cereals, Canadian journal of research 26(5) (1948) 496-500.

[21] E. Frutos, MP. Galindo, V. Leiva, An interactive biplot implementation in R for modeling genotype-byenvironment interaction, Stochastic Environmental Research and Risk Assessment 28(7) (2014) 1629-1641.

[22] PW. Hedrick, Gametic disequilibrium measures: proceed with caution, Genetics 198(117) (1987) 331-374.

[23] BS. Weir, Genetic data analysis II: methods for discrete populations genetic data, Sinauer Associates, Sunderland (1996).

[24] F. Breseghello, MS. Sorrells, Association mapping of kernel size and milling quality in wheat (Triticum aestivum L.) cultivars, Genetics 172(2006) 1165-1177.

[25] AE. Lipka, F. Tian, Q. Wang, J. Peiffer, M. Li, PJ. Bradbury et al, GAPIT: genome association and prediction integrated tool, Bioinformatics 28(18) (2012) 2397-2399. 
[26] JM. Thornsberry, MM. Goodman, J. Doebley, S. Kresovich, D. Nielsen, ES. Buckler, Dwarf polymorphisms associate with variation in flowering time, Nat Genet 28(2001) 286-289.

[27] J. Yu, G. Pressoir, WH. Briggs, I. Vroh, M. Yamasaki, JF. Doebley, MD. McMullen, BS. Gaut, DM. Nielsen, JB. Holland, S. Kresovich, ES. Buckler, A unified mixed-model method for association mapping that accounts for multiple levels of relatedness, Nat Genet 38(2006) 203-208.

[28] J. Massman, B. Cooper, R. Horsley, S. Neate, S. Dill-Macky Chao, Y. Dong, P. Schwarz, GJ. Muehlbauer, KP. Smith, Genome-wide association mapping of fusarium head blight resistance in contemporary barley breeding germplasm, Mol Breed 27(2011) 439-454.

[29] F. Detering, E. Hunter, G. Uszynski, P. Wenzl, K. Andrzej, A consensus genetic map of wheat: ordering 5,000 Wheat DArT markers, 20th ITMI \& 2nd WGC Workshop, 1-5 September, Beijing (2010).

[30] A. Jighly, R. Joukhadar, M. Alagu, SimpleMap: A Pipeline to Streamline High-Density Linkage Map Construction, The Plant Genome 8(2) (2015a) doi:10.3835/plantgenome2014.09.0056.

[31] K. Yamashita, Cultivated plants and their relatives, Results of the Kyoto University Scientific Expedition to the Karakoram and Hindukush, 1955, Vol. I. Japan: Koei Printing (1965).

[32] Q. Sohail, A. Manickavelu, T. Ban, Genetic diversity analysis of Afghan wheat landraces (Triticum aestivum) using DArT markers, Genet Resour Crop Evol 62(2015) 1147-1157.

[33] W. Tadesse, FC. Ogbonnaya, A. Jighly, M. Sanchez-Garcia, Q. Sohail, S. Rajaram et al, Genome-wide association mapping of yield and grain quality traits in winter wheat genotypes, PLoS ONE 10(10) (2015) e0141339.

[34] J. Crossa, J. Burgueno, S. Dreisigacker, M. Vargas, SA. Herrera-Foessel, M. Lillemo, RP. Singh, R. Trethowan, M. Warburton, J. Franco, M. Reynolds, JH. Crouch, R. Ortiz, Association analysis of historical bread wheat germplasm using additive genetic covariance of relatives and population structure, Genetics 177(2007) 1889-1913.

[35] S. Dreisigacker, V. Arief, I. DeLacy, G. Davenport, Y. Manes, M. Reynolds, S. Ravi, M. Dieters, J. Crossa, Patterns of linkage disequilibrium in multiple populations, In: Appels R, Eastwood R, Lagudah E, Langridge P, Mackay M, McIntyre L, Sharp P (eds) Proceedings of 11th international wheat genet symposium, Sydney University Press, Brisbane, pp 1-5 (2008).

[36] R. Joukhadar, M. El-Bouhssini, A. Jighly, FC. Ogbonnaya, Genome-wide association mapping for five major pest resistances in wheat, Mol Breed 32(2013) 943-960.

[37] MA. Mulki, A. Jighly, G. Ye, LC. Emebiri, D. Moody, O. Ansari, FC. Ogbonnaya, Association mapping for soil borne pathogen resistance in synthetic hexaploid wheat, Mol Breed 3(2013) 299-311. 
[38] T. Letta, P. Olivera, M. Maccaferri, Y. Jin, K. Ammar, A. Badebo, S. Salvi, E. Noli, J. Crossa, R. Tuberosa, Association mapping reveals novel stem rust resistance loci in Durum wheat at the seedling stage, Plant Genome (2014) doi:10.3835/plantgenome2013.08.0026.

[39] W. Tadesse, FC. Ogbonnaya, A. Jighly, K. Nazari, S. Rajaram, M. Baum, Association mapping of quantitative resistance to stripe rust in winter wheat cultivars and elite genotypes targeted to the CWANA region, Crop Sci 54(2) (2014) 607-616.

[40] Y. Ren, ZH. He, J. Li, M. Lillemo, L. Wu, B. Bai, QX. Lu, HZ. Zhu, G. Zhou, JY. Du, QL. Lu, XC. Xia, QTL mapping of adult-plant resistance to stripe rust in a population derived from common wheat cultivars Naxos and Shanghai 3/Catbird, Theor Appl Genet 125(2012) 1211-1221.

[41] GM. Rosewarne, SA. Herrera-Foessel, RP. Singh, J. Huerta-Espino, CX. Lan, ZH. He, Quantitative trait loci of stripe rust resistance in wheat, Theor Appl Genet 126(10) (2013) 2427-2449.

[42] GM. Rosewarne, RP. Singh, J. Huerta-Espino, SA. Herrera-Foessel, KL. Forrest, MJ. Hayden, GJ. Rebetzke, Analysis of leaf and stripe rust severities reveals pathotype changes and multiple minor QTLs associated with resistance in an Avocet $\times$ Pastor wheat population, Theor Appl Genet 124(2012) 12831294.

[43] F. Lin, XM. Chen, Quantitative trait loci for non-race-specific, high-temperature adult-plant resistance to stripe rust in wheat cultivar Express, Theor Appl Genet 118(2009) 631-642.

[44] M. Lillemo, B. Asalf, RP. Singh, J. Huerta-Espino, XM. Chen, ZH. He, Å. Bjørnstad, The adult plant rust resistance loci Lr34/Yr18 and Lr46/Yr29 are important determinants of partial resistance to powdery mildew in bread wheat line Saar, Theor Appl Genet 116(2008) 1155-1166.

[45] RS. Zwart, JP. Thompson, AW. Milgate, UK. Bansal, PM. Williamson, H. Raman, HS. Bariana, QTL mapping of multiple foliar disease and root-lesion nematode resistances in wheat, Mol Breed 26(2010) $107-124$.

[46] GM. Rosewarne, RP. Singh, J. Huerta-Espino, GJ. Rebetzke, Quantitative trait loci for slow-rusting resistance in wheat to leaf rust and stripe rust identified with multi-environment analysis, Theor Appl Genet 116(2008) 1027-1034.

[47] HS. Bariana, UK. Bansal, A. Schmidt, A. Lehmensiek, J. Kaur, H. Miah, N. Howes, CL. McIntyre, Molecular mapping of adult plant stripe rust resistance in wheat and identification of pyramided QTL genotypes, Euphytica 176(2010) 251-260.

[48] MD. Vazquez, CJ. Peterson, O. Riera-Lizarazu, X. Chen, A. Heesacker, K. Ammar, J. Crossa, CC. Mundt, Genetic analysis of adult plant, quantitiative resistance to stripe rust in wheat cultivar 'Stephens' in multienvironment trials, Theor Appl Genet 124(2012) 1-11. 
[49] HS. Bariana, MJ. Hayden, NU. Ahmed, JA. Bell, PJ. Sharp, RA. McIntosh, Mapping of durable adult plant and seedling resistances to stripe rust and stem rust diseases in wheat, Aust J Agric Res 52(2001) 12471255.

[50] VP. Ramburan, ZA. Pretorius, JH. Louw, LA. Boyd, PH. Smith, WHP. Boshoff, R. Prins, A genetic analysis of adult plant resistance to stripe rust in wheat cultivar Kariega, Theor Appl Genet 108(2004) $1426-1433$.

[51] JPE. Melichar, S. Berry, C. Newell, R. MacCormack, LA. Boyd, QTL identification and microphenotype characterisation of the developmentally regulated yellow rust resistance in the UK wheat cultivar Guardian, Theor Appl Genet 117(2008) 391-399.

[52] P. Chhuneja, S. Kaur, T. Garg, M. Ghai, S. Kaur, M. Prashar, NS. Bains, RK. Goel, B. Keller, HS. Dhaliwal, K Singh, Mapping of adult plant stripe rust resistance genes in diploid A genome wheat species and their transfer to bread wheat, Theor Appl Genet 116(2008) 313-324.

[53] CX. Lan, SS. Liang, XC. Zhou, G. Zhou, QL. Lu, XC. Xia, ZH. He, Identification of genomic regions controlling adult-plant stripe rust resistance in Chinese landrace Pingyuan 50 through bulked segregant analysis, Phytopathology 100(2010) 313-318.

[54] S. Mallard, D. Gaudet, A. Aldeia, C. Abelard, AL. Besnard, P. Sourdille, F. Dedryver, Genetic analysis of durable resistance to yellow rust in bread wheat, Theor Appl Genet 110(2005) 1401-1409.

[55] YM. Lu, CX. Lan, SS. Linag, XC. Zhou, D. Liu, G. Zhou, QL. Lu, JX. Jing, MN. Wang, XC. Xia, ZH. He, QTL mapping for adult-plant resistance to stripe rust in Italian common wheat cultivars Libellula and Strampelli, Theor Appl Genet 119(2009) 1349-1359.

[56] J. Feng, LL. Zuo, ZY. Zhang, RM. Lin, YY. Cao, SC. Xu, Quantitative trait loci for tempertature-sensitive resistance to Puccinia striiformis f. sp. tritici in wheat cultivar Flinor, Euphytica 178(2011) 321-329.

[57] YF. Hao, ZB. Chan, YY. Wang, D. Bland, J. Buck, G. Brown-Guedira, J. Johnson, Characterization of a major QTL for adult plant resistance to stripe rust in US soft red winter wheat, Theor Appl Genet 123(2011) 1401-1411.

[58] EN. Yang, GM. Rosewarne, SA. Herrera-Foessel, J. Huerta-Espino, ZX. Tang, CF. Sun, ZL. Ren, RP. Singh, QTL analysis of the spring wheat "Chapio" identifies stable stripe rust resistance despite intercontinental genotype $\times$ environment interactions, Theor Appl Genet 126(2013) 1721-1732.

[59] EA. Milus, K. Kristensen, MS. Hovmoller, Evidence for increased aggressiveness in a recent widespread strain of Puccinia striiformis f. sp. tritici causing stripe rust of wheat, Phytopathology 99(2009) 89-94.

[60] DP. Hodson, Shifting boundaries: challenges for rust monitoring, Euphytica 179(2011) 93-104. 
[61] RW. Stubbs, JM. Prescot. EE. Saari, HJ. Dubi, Cereal Disease Methodology Manual. Centro Internacional de Mejoramiento de Maizey Trigo (CIMMYT), Mexico, 1986, Pages: 46.

[62] W. Yan, GGEBiplot - a Windows application for graphical analysis of multi-environment trial data and other types of two-way data, Agron J 93(2001) 1111-1118. 
Table 1. Details of Field screening of Stripe rust in Afghan Wheat Landraces. DS: disease severity, DR: disease reaction, CI: coefficient of infection, T: Toluca, K: Kabul, BB: Badambagh, E: early, L: late, H: Herat, SBES: Jalalabad station.

\begin{tabular}{|c|c|c|c|c|}
\hline No. & $\begin{array}{c}\text { Trial Name } \\
\text { (Year) }\end{array}$ & Location & $\begin{array}{c}\text { No. of } \\
\text { accessions }\end{array}$ & Rust Scoring \\
\hline 1 & $\begin{array}{c}\text { T11 } \\
(2011-12)\end{array}$ & $\begin{array}{c}\text { Toluca Experiment Station, CIMMYT, } \\
\text { Mexico }\end{array}$ & 352 & DR \\
\hline 2 & $\begin{array}{c}\text { K11 } \\
(2011-12)\end{array}$ & $\begin{array}{c}\text { Darulaman Research Station, Kabul, } \\
\text { Afghanistan }\end{array}$ & 352 & DR, DS, CI \\
\hline 3 & $\begin{array}{c}\text { BB-E12 } \\
(2012-13)\end{array}$ & $\begin{array}{c}\text { Badambagh Research Station, Kabul, } \\
\text { Afghanistan }\end{array}$ & 321 & DR, DS, CI \\
\hline 4 & $\begin{array}{c}\text { BB-L12 } \\
(2012-13)\end{array}$ & $\begin{array}{c}\text { Badambagh Research Station, Kabul, } \\
\text { Afghanistan }\end{array}$ & 321 & DR, DS, CI \\
\hline 5 & $\begin{array}{c}\text { H12 } \\
(2012-13)\end{array}$ & $\begin{array}{c}\text { Urdu Khan Regional Agricultural Research } \\
\text { Station, Herat, Afghanistan }\end{array}$ & 313 & DR, DS, CI \\
\hline 6 & $\begin{array}{c}\text { SBES12 } \\
(2012-13)\end{array}$ & $\begin{array}{c}\text { Agricultural Research Station, Jalalabad, } \\
\text { Afghanistan }\end{array}$ & 313 & DR, DS, CI \\
\hline 7 & $\begin{array}{c}\text { T12 } \\
(2012-13)\end{array}$ & Toluca Research Station, CIMMYT, Mexico & 339 & DS \\
\hline 8 & $\begin{array}{c}\text { H13 } \\
(2013-14)\end{array}$ & $\begin{array}{l}\text { Urdu Khan Regional Agricultural Research } \\
\text { Station, Herat, Afghanistan }\end{array}$ & 319 & DR, DS, CI \\
\hline
\end{tabular}


Table 2. Stripe rust resistance QTL identified in both subset and full analysis. Chr: chromosome; Pos: position; MAF: minor allele frequency; DR: disease reaction; DS: disease severity; CI: coefficient of infection; T: Toluca; K: Kabul; BB: Badambagh; E: early; L: late; H: Herat; NA: not applicable.

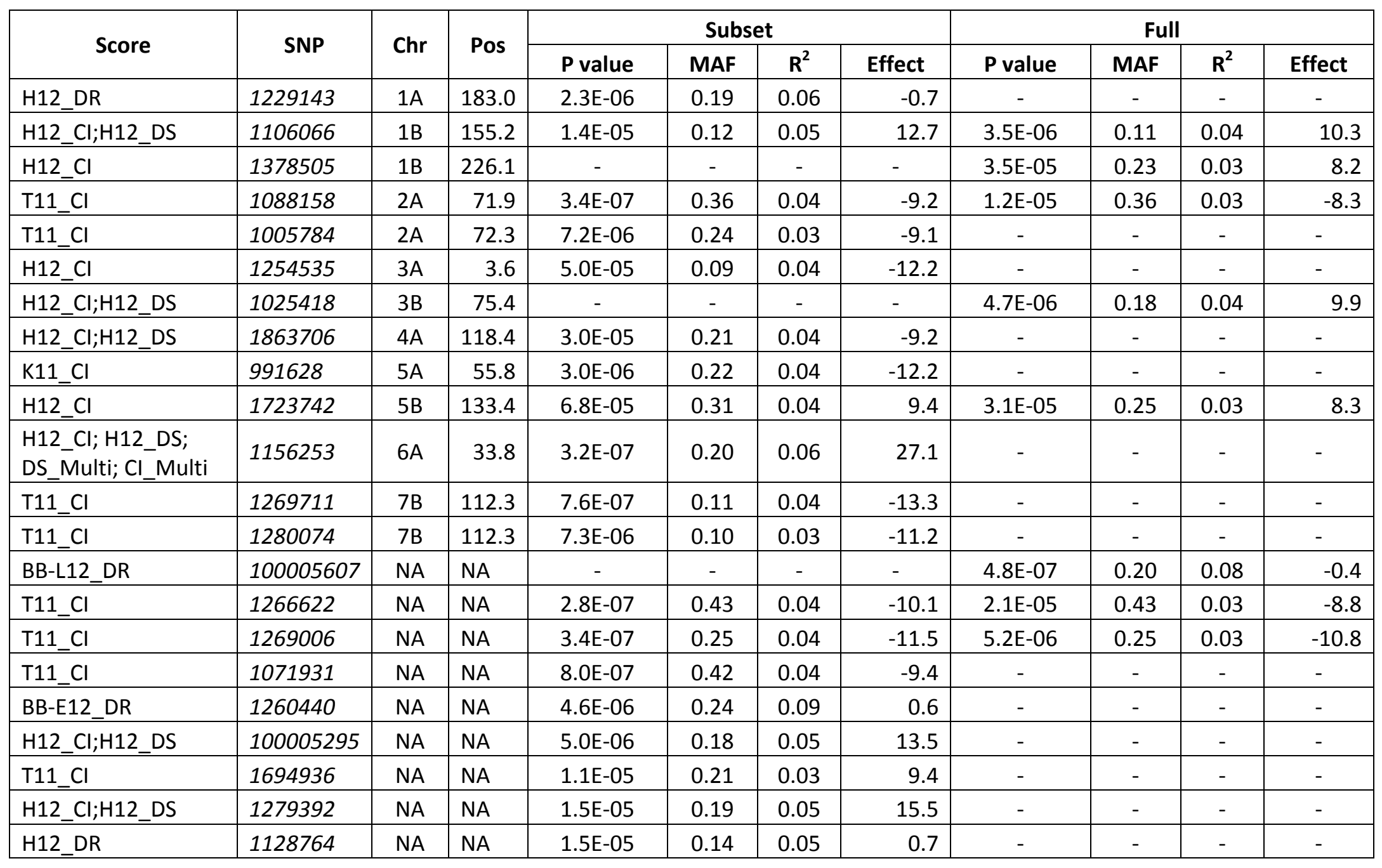




\begin{tabular}{|c|c|c|c|c|c|c|c|c|c|c|c|}
\hline $\mathrm{K} 11 \_\mathrm{Cl}$ & 100000832 & NA & NA & $1.6 \mathrm{E}-05$ & 0.23 & 0.04 & -12.7 & - & - & - & - \\
\hline T11_Cl & 1669827 & NA & NA & $3.9 \mathrm{E}-05$ & 0.47 & 0.02 & 7.6 & - & - & - & - \\
\hline $\mathrm{H} 12$ Cl;H12_DS & 1106038 & NA & NA & $4.5 \mathrm{E}-05$ & 0.12 & 0.04 & -12.5 & - & - & - & - \\
\hline $\mathrm{H} 12$ Cl;H12_DS & 1069981 & NA & NA & $5.8 \mathrm{E}-05$ & 0.33 & 0.04 & -10.5 & - & - & - & - \\
\hline
\end{tabular}




\section{Figure Legends:}

Figure 1. GGE biplot analysis of Afghan wheat landrace against stripe rust resistance in different environments using the coefficient of resistance score

Figure 2. A heatmap showing the kinship and phylogenetic relations of Afghan wheat landrace. The same phylogeny is shown in the left and above the heatmap. Red colours represent high kinship relations while lighter colours shows continuous weaker relations. Genotypes in the red square were removed in the subset analysis. 


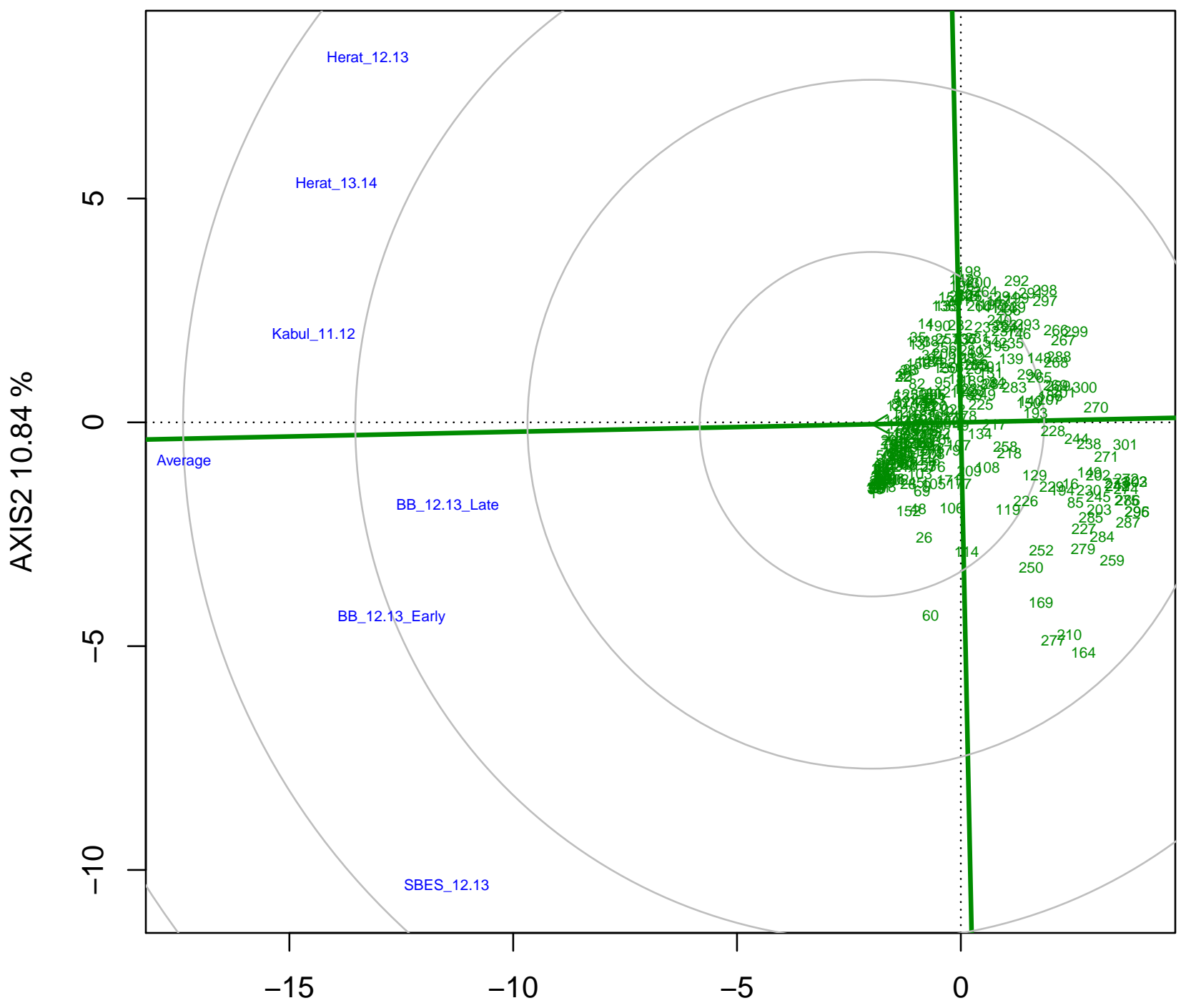

AXIS1 $61.75 \%$ 
$\begin{array}{cc}\text { Figure } 2 & \begin{array}{c}\text { Color Key } \\ \text { and Histogram }\end{array}\end{array}$
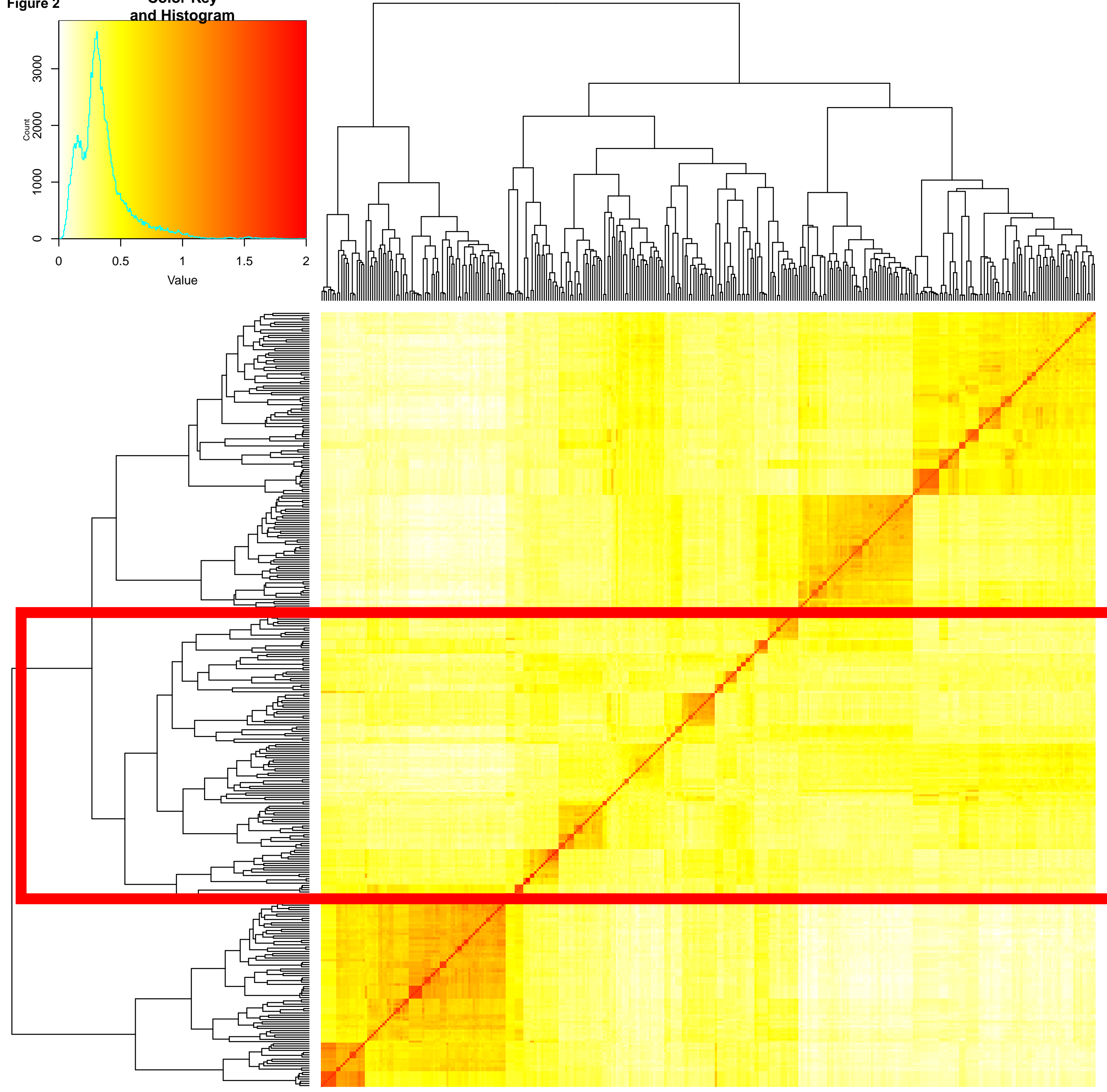